\title{
Climate sceptics place bets on world cooling down
}

A British climate modeller has finally persuaded global-warming sceptics to wager money on their contrarian predictions about climate change.

James Annan, who is based at the Japan Agency for Marine-Earth Science and Technology in Yokohama, has agreed a US\$10,000 bet with Galina Mashnich and Vladimir Bashkirtsev, two solar physicists who argue that global temperatures are driven by changes in the Sun's activity and will fall over the next decade. The bet, which both sides say they are willing to formalize in a legal document, came after other climate sceptics refused to wager money.

Annan began his quest last winter after hearing Richard Lindzen, a meteorologist at the Massachusetts Institute of Technology who questions the extent to which human activities are influencing climate, say he was willing to bet that global temperatures will drop over the next 20 years. "A pay-off at retirement age would be a nice top-up to my pension," says Annan.

But no wager was ever agreed. Annan says that Lindzen wanted odds of 50-to-1 against falling temperatures: this meant that Annan would pay out $\$ 10,000$ if temperatures dropped, but receive only $\$ 200$ if they rose. In total, Annan says he tried and failed to agree terms with seven sceptics.

Other potential climate gamblers have drawn a blank with their attempts to enter similar bets with climate-change sceptics. In May, environmental activist George Monbiot challenged climate sceptic Myron

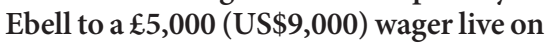

$\mathrm{BBC}$ radio. Ebell, a global-warming specialist at the Competitive Enterprise Institute, a think-tank in Washington DC, declined, saying he has four children to put through university and so does not "want to take risks".

But Annan's search ended with Mashnich and Bashkirtsev, who are based at the Institute of Solar-Terrestrial Physics in Irkutsk, Russia. They say that global surface air temperatures closely correlate with the size and number of sunspots. Sunspot levels follow regular patterns and the Sun is expected to be in a less active phase over the next few decades, leading Mashnich and Bashkirtsev to predict a drop in temperature.

Both sides have agreed to compare the average global surface temperature between 1998 and 2003 with that between 2012 and 2017, as defined by the records of the US National Climatic Data Center. If the temperature drops, Annan will pay Mashnich and Bashkirtsev $\$ 10,000$ in 2018, with the same sum going the other way if the temperature rises.

Piers Corbyn, head of Weather Action, a private meteorological service based in London, told Nature he would like to enter into a similar bet. Corbyn's theory, the details of which he has not revealed, predicts that changes in solar activity will cause "considerable world cooling" by 2040. Annan challenged him to a bet in May, but Corbyn says he did not receive the e-mail. "I'm happy to bet loads of money," he says. Jim Giles

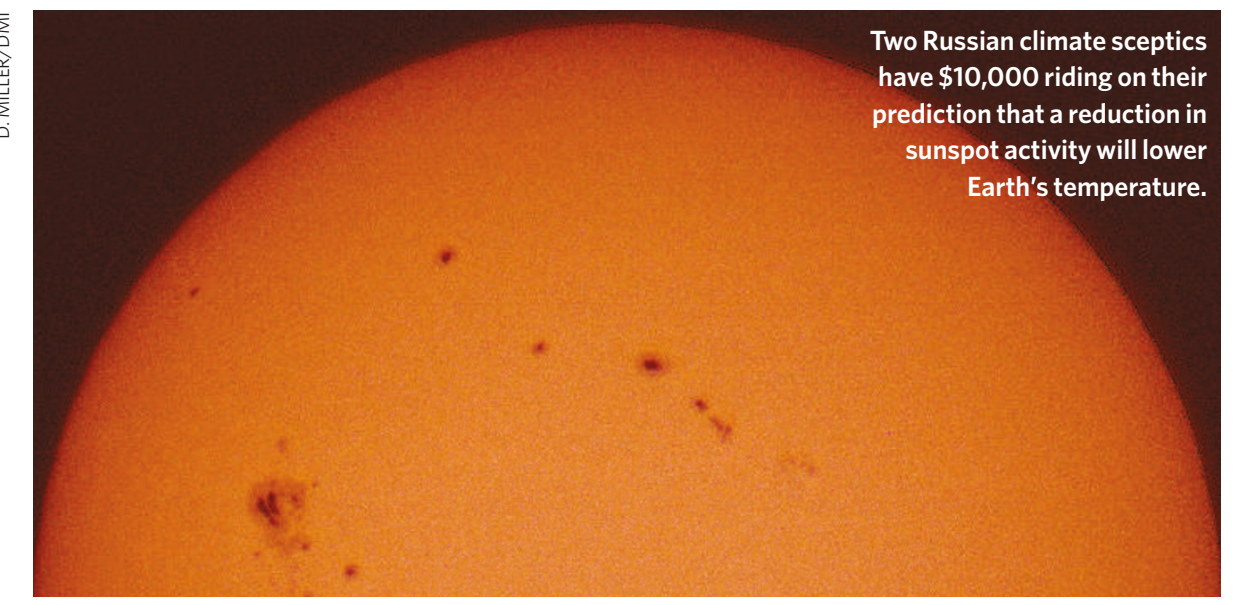

Two Russian climate sceptics have $\$ 10,000$ riding on their rediction that a reduction in sunspot activity will lower Earth's temperature. 